\title{
BEACH PROFILE USING UNMANNED AERIAL VEHICLE IMAGERY
}

\author{
NASUHA MOHD SHAFFIE ${ }^{1}$ AND EFFI HELMY BIN ARIFFIN ${ }^{1,2^{*}}$
}

${ }^{\prime}$ Faculty of Science and Marine Environment, Universit Malaysia Terengganu, 21030 Kuala Nerus, Terengganu, Malaysia. ${ }^{2}$ Institute of Oceanography and Environment, Universiti Malaysia Terengganu, 21030 Kuala Nerus, Terengganu, Malaysia.

*Corresponding author: effihelmy@umt.edu.my

http://doi.org/10.46754/umtjur.2021.10.010

\begin{abstract}
The advancement of technology has allowed the application of Unmanned Aerial Vehicle (UAV) for beach surveying to be used instead of theodolite method. This is still a debatable issue whether UAV can completely replace the theodolite method for future research. The studied area at Seberang Takir, Kuala Nerus is recognized as a critical erosion site and beach nourishment activity has been undertaken here on an approximately five year cycle. This study aims to show the potential of UAV application for coastal research. The results show that the elevation data of drone extracted from Digital Elevation Model (DEM) are match equivalent to the total station elevation data within $0.03 \mathrm{~m}$. The beach profile graph of the drone and total station show significant differences in the steeper area. This study shows that the UAV image technique using a drone holds the potential for monitoring and quantifying the beach changes to levels of accuracy and precision that can be compared to the theodolite method. UAV has a big potential for beach monitoring and it is encouraged to be applied for further understanding of how and when they can be most useful.
\end{abstract}

Keywords: Beach profile, total station, UAV.

\section{Introduction}

Coastal area is an environment that holds various types of sites with unique ecological, geological, geomorphological, landscape, or cultural heritage values that are important to be preserved (Yoo \& Oh, 2016). Natural beaches are also mostly influenced by many coastal factors such as river sediment, natural forces such as wind, waves and currents.

The coastal topography is very complex and dynamic. Precise monitoring and topographic survey implementation are needed to monitor the constant changes in beach topography for environmental protection and it is very fundamental in coastal management.

Beach surveys and in-situ monitoring have been traditionally performed for the measurement of beach topography using several methods such as Global Navigation Satellite Systems - Real-Time Kinematic (GNSS-RTK) or total station where the results are very accurate along the measured transects (Harley et al., 2011). These methods are always used in beach profiling to determine the changes of sediment volume of coastal where this method can be used in the evaluation procedure for various schemes (Yoo \& Oh, 2016).

However, there are a few limitations with the traditional survey method as it sometimes takes too much time, study area is not suitable for in-situ surveyed and the cost of the survey can be costly depending on the circumstances (Shaw et al., 2019). The UAV system is one of the lowcost and most efficient equipment for image acquisition (Yoo \& Oh, 2016) to be compared to traditional method. UAV can hover at low altitudes and produce a very high-resolution image. It is also a promising alternative for a low-cost flight mission to be used in surveying.

Nevertheless, some researchers thought that using a drone as a photogrammetric method is very challenging especially in beach environments as low texture and contrast of the sand surface make it harder to match distinct features between different images (Turner et al., 2016). So, the use of drone needs to be investigated further. The purpose of this research therefore is to determine the differences and accuracy of the beach profile using UAV imagery. 


\section{Methodology}

\section{Study Site}

Figure 1 shows the study area that is located at Seberang Takir in the district of Kuala Nerus, Terengganu, Malaysia. It is situated in the east coast of Kuala Terengganu which is located on the eastern part of Peninsular of Malaysia. The coastal water is less than 50 nautical miles from shore and is quite shallow with the deepest area being about $50 \mathrm{~m}$. The annual mean air temperature ranges from $24^{\circ} \mathrm{C}$ to $28^{\circ} \mathrm{C}$ with an average humidity of approximately $80 \%$ (Marghany et al., 2012).
The beaches are fully utilized for tourism activities based on observation. The beach has a little presence of vegetation and more focused on tourism. This area is also involved in the 'Tourism Gateway' project that was implemented in 2010 by the federal government collaborating with the state government through the council of the East Coast Economic Region (ECER). The sand volume in the study area is high due to beach nourishment activity that has been undertaken here on an approximately five year cycle (Chalabi et al., 2006).

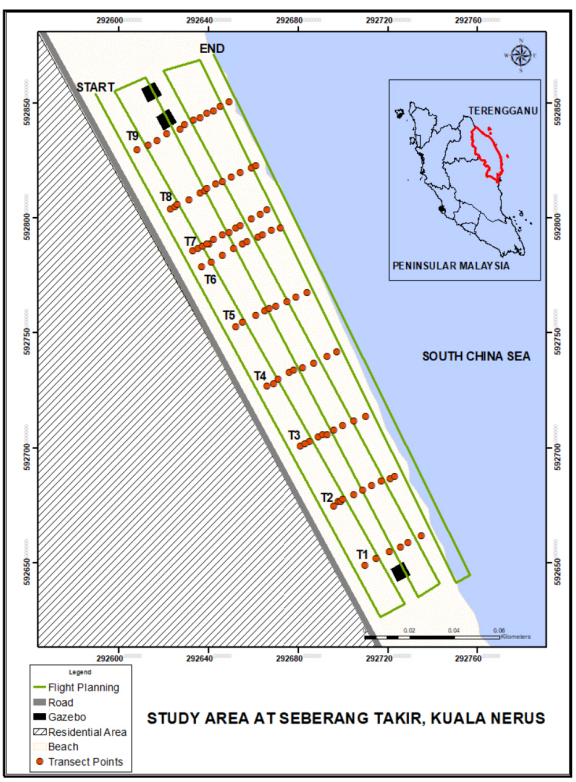

Figure 1: Study area

\section{Total Station}

The Topcon GPT-3100N is composed of an electronic theodolite with an electronic distance meter (EDM) (Figure 2). This method was executed with a two-person operation based on Figure 3, where one person held a prism (on a pole/staff) over each feature required to be recorded while the other person would take a reading to the prism by focusing on it through the optics of the instruments (Oniga et al., 2018). The readings were adjusted to the DTGSM datum level and nine transects (T1-T9) were recorded containing two benchmarks, 29 Ground Control Points (GCPs) and 93 points. The GCPs were used in the process of indirectly georeferencing drone images where GCPs were recorded at the presence of trees and buildings. 


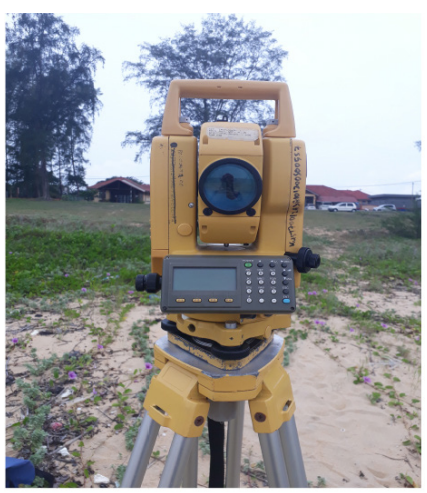

Figure 2: Total station

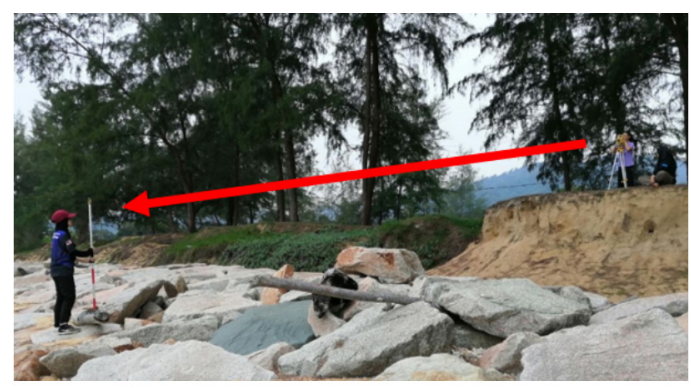

Figure 3: Total station survey execution

\section{UAV Survey}

The system is composed of a drone with a remote controller a standard tablet with a planning software or application (Laporte-Fauret et al., 2019). The images are captured by using DJI Mavic Pro (Figure 4). The device has maximum resolution of 12.71 Mpixel with a $78.8^{\circ}$ field of view (FOV), with a $35-\mathrm{mm}$ equivalent focal length of $26 \mathrm{~mm}$ and a f/2.2 aperture. The UAV is equipped with $3830 \mathrm{mAh}$ smart batteries which allows a net flight time of nearly 27 minutes per battery, totaling of one hour per field session. During the flight, the drone position, the battery, status, and the captured images will be continuously monitored on the remote screen. The drone is semi-automated system operated by UAV pilot.

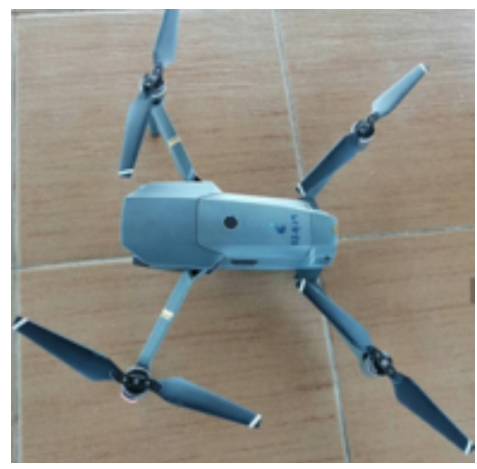

Figure 4: DJI Mavic Pro 
Utilizing Mission HUB Litchi software for flight planning, the grid mission for flight path was selected and the home point was set up. Based on Figure 1, the drone flew along the pathway and captured images of the beach and measured the beach topography for 12 minutes at $120 \mathrm{~m}$ altitude. As a result, the drone captured the image of the beach in UTM coordinate containing 248 images and three videos collected for data processing.

\section{DEM Generation}

Aerial images collected during the flight were processed by using Agisoft Photoscan (Figure 5) Pro version 1.4.5 (Casella et al., 2020) which produced orthophoto and DEM of the beach. For precise georeferencing and to minimize horizontal and vertical, 12 GCPs were added to acquire more accurate images. The alignment parameters were set to "high", dense point cloud generation was executed with "high" settings and depth filtering mode set to "aggressive." The dense cloud was the source used to build the DEMs with interpolation enabled. The elevation data were extracted from DEM using Arcmap 10.8 software to create and execute beach profile analysis.

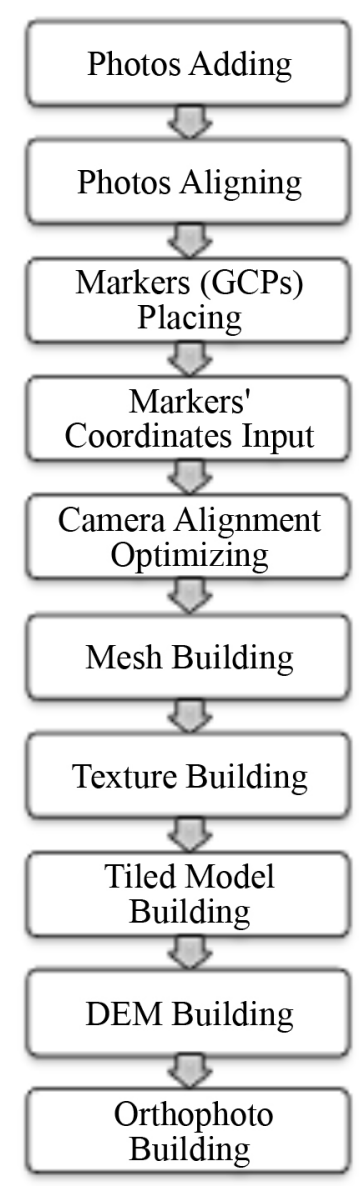

Figure 5: DEM generation methodology flowchart 


\section{Accuracy Assessment}

For each point, two elevation values were used: one from a total station and the other from a drone. The differences of elevation from both instruments were determined as shown in Equation (1):

Error in elevation = elevation from Drone elevation from Total Station

The whole set of data was summarized with a single value by calculating RMSE in elevation. The RMSE was carried out (Udin \& Ahmad, 2014) using the equation shown in Equation (2):

$$
R M S E= \pm \sqrt{\frac{\sum\left(n_{1}-n_{2}\right)^{2}}{N-1}}
$$

Where, $\mathrm{n}_{1}$ is the differences values between two parameters, $n_{2}$ is the mean differentiation and $n_{3}$ is the number of points.

\section{Results and Discussion}

Elevation data extracted from a drone and total station created a beach profile graph of total station and drone as shown in Figure 6. From the graphs, there are not many differences and they show the same shape and curve from both techniques. However, some significant differences started to appear in $20 \mathrm{~m}$ distance toward the end of the profile in Transect 1 due to the presence of breakwater. In Transect 2, there are small differences in $20 \mathrm{~m}$ distance toward the end of the profile where the drone showed a smooth linear line compared to a total station that showed more steepness at the beginning of the profile. In Transect 3, at the beginning and at the end of the profile, differences in slopes between total station and drone are seen but in the middle of the steepness, total station and drone overlapped each other which shows that the value of elevation from both methods are close to each other.

In Transect 4, large differences of the slopes appeared in the first $10 \mathrm{~m}$ of the profile and at the end of the profile. In Transect 5, significant differences of slopes only appeared in the first $20 \mathrm{~m}$ of the profile. In Transect 6 and Transect 7 , both transects showed small differences of the slope in the first $20 \mathrm{~m}$ of the profile but showed differences between slopes at the end of the profile. In Transect 8 , significant differences of slopes appeared from $30 \mathrm{~m}$ until the end of the profile. In Transect 9, the differences started to show in the distance of $20 \mathrm{~m}$ and the differences become larger and more significant toward the end of the profile due to the presence of vegetation and gazebo. 
a)

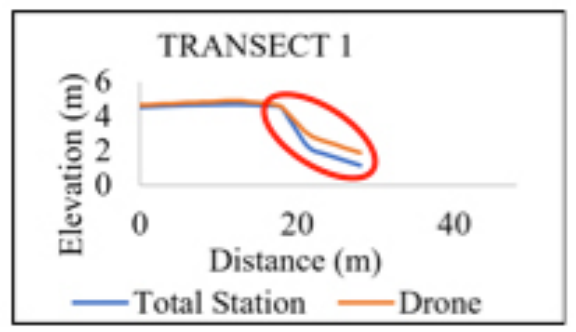

c)

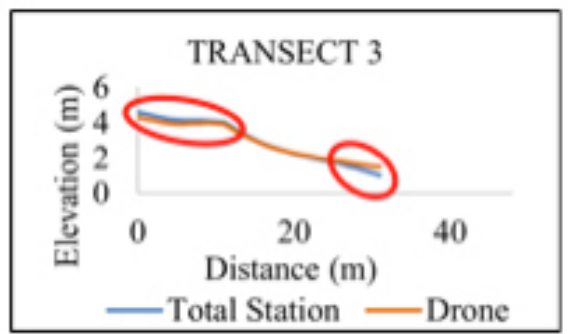

e)

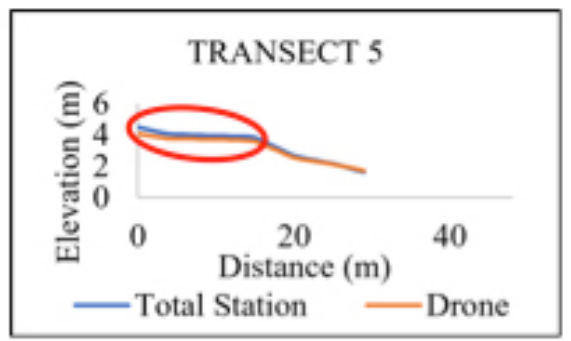

g)

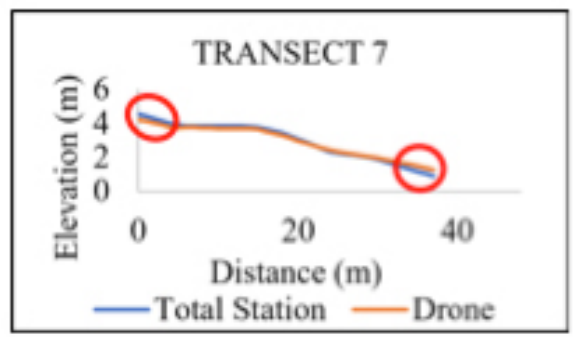

b)

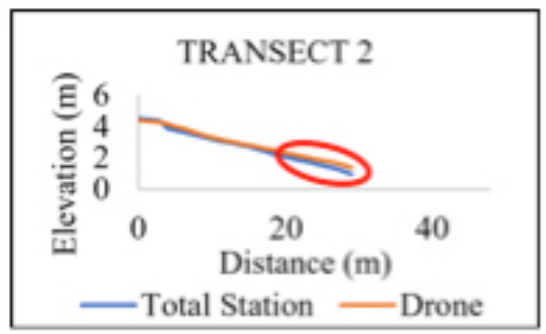

d)

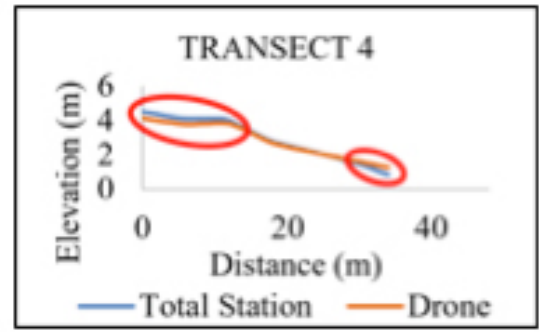

f)

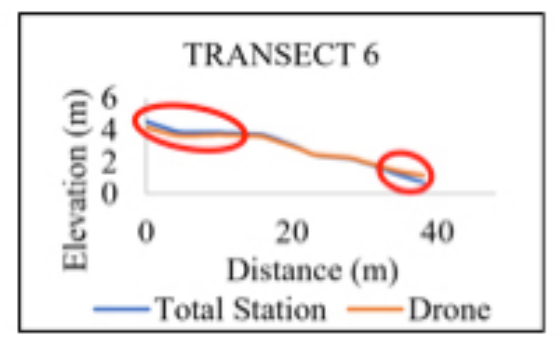

h)

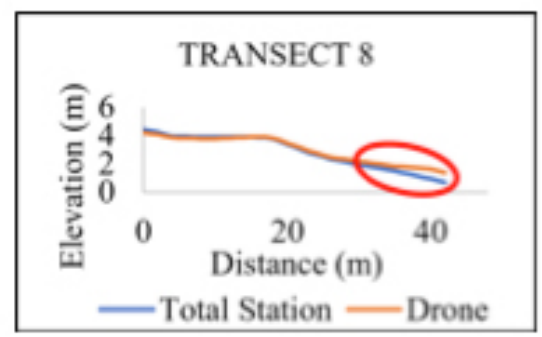

i)

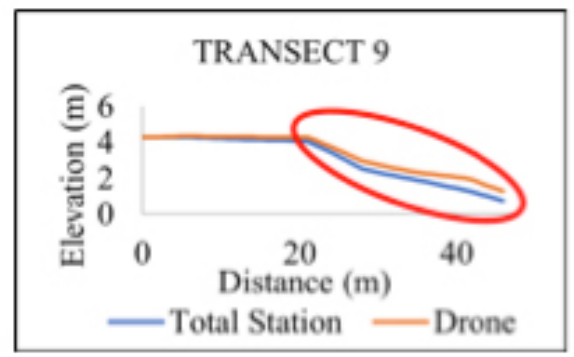

Figure 6: Beach profile graphs of total station (blue) and drone (red) 
Beach profile graphs show the differences in elevation value between a total station and drone. The profile of drone shows the same pattern to the profile of total station. However, it has quite a big difference in value, especially in the steeper area where drone overestimated the lower elevation of the profiles. The slope appears less precise due to the surface condition where it has various slope angles that can affect the results due to the lens limitation of drone (Tahar, 2015). Transect 1 and Transect 9 have the most significant difference of slope due to the presence of a gazebo and breakwater. The breakwater area is very dangerous to for setting up the theodolite instrument resulting in only a few GCPs being planted in these areas because it is not convenient and very hard to access. Since drone derived DEM can be valid in the area limited by the GCPs (Trembanis et al., 2017), the extracted value for elevation can be less accurate and can show big differences.

The 3D coordinates obtained from total stations were used as a reference value for accuracy assessment. The results from RMSE calculation between differences in elevation of total station and drone revealed that drone was able to retrieve the beach profile accurately. Table 1 shows the RMSE, comparing 87 total station point measurements. Drone obtained $0.031 \mathrm{~m}$ from all transects and they yielded RMSE ranges of $0.05-0.18 \mathrm{~m}$. Transect 7 achieved the smallest RMSE value which is $0.056 \mathrm{~m}$ compared to Transect 1 which obtained $0.186 \mathrm{~m}$. The difference between the highest and smallest RMSE values is $0.13 \mathrm{~m}$. Transects 2, 3, 5 and 6 obtained about $0.07 \mathrm{~m}$ of RMSE value as seen from the result, which is fairly accurate to be compared to total station.

Total Station obtained 0.019 and ranging from $0.01-0.18 \mathrm{~m}$. Transects 7 and 8 achieved the smallest RMSE values which are 0.018 and $0.019 \mathrm{~m}$ respectively, compared to Transect 8 , obtained $0.183 \mathrm{~m}$, marking it as the highest RMSE value for total station. It has $0.165 \mathrm{~m}$ difference between the highest and the smallest value of RMSE. Transects 1 and 5 obtained RMSE values more than $0.1 \mathrm{~m}$ while other transects obtained less than $0.04 \mathrm{~m}$. The huge gap values between transects can be due to different number of points recorded at each transect which influences the details in the output DEM.

Table 1: Accuracy assessment value

\begin{tabular}{ccc}
\hline Transect & Drone $(\mathbf{m})$ & Total Station $(\mathbf{m})$ \\
\hline 1 & 0.186 & 0.183 \\
2 & 0.076 & 0.026 \\
3 & 0.076 & 0.027 \\
4 & 0.092 & 0.036 \\
5 & 0.076 & 0.117 \\
6 & 0.071 & 0.029 \\
7 & 0.056 & 0.018 \\
8 & 0.086 & 0.019 \\
9 & 0.146 & 0.027 \\
\hline All transects & 0.031 & 0.019 \\
\hline
\end{tabular}

Total station and drone showed a similar range in RMSE values. Drone had slightly higher values compared to total station. Drone had the highest RMSE of $0.186 \mathrm{~m}$ and total station had the lowest of 0.018. Conversely, the RMSE for both methods were derived from DEM, so it should be noted that there are disparities between the methods the density and number of points are recorded by each method. Hence, there are differences in grid spacing of each survey which influence the detail in the output DEM (Moloney, 2018). This achievable accuracy 
was also dependent on the configuration of the photographs that affect the production of DEM and orthophoto. The presence of GCPs gives a direct impact on accuracy (Udin \& Ahmad, 2014), quality of orthophoto and DEM accuracy (Tahar, 2015).

The use of drone as a monitoring tool is a great insight because it can provide data at high and adjustable frequency, easy to generate topographic maps and is time saving on data collection. The analysis of the results showed that the use of UAV in monitoring is likely a beneficial strategy with GCP. If the area to be mapped or surveyed is not accessible for certain reasons, not only for coastal application but also aspect as well, the GCP can be surveyed on the edge of the flight plan and can obtain good final accuracies of the model. However, the number of images to be both acquired and further processed is higher which may influence the overall performance in terms of time needed to generate the final model (Taddia et al., 2019).

\section{Conclusion}

This paper focuses on the UAV survey at the beach area with the use of the theodolite method. In this research study, the theodolite method using a total station and UAV methods were assessed and analyzed. The study shows that orthophoto and DEM are very accurate and able to achieve fast results. To obtain a good result, UAV acquisition is fundamental, especially during flight planning where the high percentage of the overlapping of images affects the results. In addition, a high number of GCPs should be included during fieldwork. As orthophoto and DEM generated, accuracy assessment and beach profile can be executed and created. With RMSE value of $0.03 \mathrm{~m}$ and $\mathrm{R}^{2}$ value of 0.97 , the accuracy of drone data using the total station as a reference proved to be accurate to be used in coastal monitoring and beach profiling.

This study also concludes with a call for more research on costs and actual impacts, documentation of factors that lead to successes and failures, and how the UAV technique divides influence monitoring outcomes. In this study, there are a few things that have been identified for future research. I would like to recommend that (1) during dense cloud process in data processing using Agisoft Photoscan, set the quality to "ultra-high" for more valid alignment accuracy of image originals and upscaled images; (2) this methodology includes infrared cameras that can be used to correct sun glints and (3) distribute GCPs throughout the area especially at the breakwater, vegetation area, and waterline to ensure the accuracy of DEM.

\section{Acknowledgements}

I would like to thank my supervisor, Dr. Effi Helmy for his guidance and expertise throughout the duration of the fieldwork and article. Besides that, I would like to extend my appreciation to the academic and general staff members of the Faculty of Science and Marine Environment and INOS of Universiti Malaysia Terengganu who have helped me with various aspects of this project. To all my beloved friends, my final year project groupmates and seniors who have helped me in conducting my fieldwork and supported me throughout my research.

\section{References}

Casella, E., Drechsel, J., Winter, C., Benninghoff, M., \& Rovere, A. (2020). Accuracy of sand beach topography surveying by drones and photogrammetry. Geo-Marine Letters, 1-14.

Chalabi, A., Mohd-Lokman, H., Mohd-Suffian, I., Karamali, K., Karthigeyan, V., \& Masita, M. (2006). Monitoring shoreline change using Ikonos image and aerial photographs: a case study of Kuala Terengganu area, Malaysia. ISPRS Commission VII Mid-term Symposium "Remote Sensing: From Pixels to Processes". Enschede, the Netherlands.

ECER (2010). Kuala Terengganu City Centre: A Vibrant Heritage Waterfront City. East Coast Economic Region Development Council (ECERDC). 
Eyoh, A., Ubom, O., \& Ekpa, A. (2019). Comparative analysis of UAV photogrammetry and total station traversing on route survey. European Journal of Engineering and Technology, 7(4).

Harley, M. D., Turner, I. L., Short, A. D., \& Ranasinghe, R. (2011). Assessment and integration of conventional, RTK-GPS and image-derived beach survey methods for daily to decadal coastal monitoring. Coastal Engineering, 58(2), 194-205.

Laporte-Fauret, Q., Marieu, V., Castelle, B., Michalet, R., Bujan, S., \& Rosebery, D. (2019). Low-Cost UAV for high-resolution and large-scale coastal dune change monitoring using photogrammetry. Journal of Marine Science and Engineering, 7(3), 63.

Marghany, M. (2012). Intermonsoon water mass characteristics along coastal waters off Kuala Terengganu, Malaysia. International Journal of Physical Sciences, 7(8), 12941299.

Moloney, J. G., Hilton, M. J., Sirguey, P., \& Simons-Smith, T. (2018). Coastal dune surveying using a low-cost remotely piloted aerial system (RPAS). Journal of Coastal Research, 34(5), 1244-1255.

Oniga, V. E., Breaban, A. I., \& Statescu, F. (2018). Determining the optimum number of ground control points for obtaining high precision results based on UAS images. Proceedings of The 2nd International Electronic Conference on Remote Sensing, 2(7), 1-11.
Shaw, L., Helmholz, P., Belton, D., \& Addy, N. (2019). Comparison of UAV lidar and imagery for beach monitoring. International Archives of the Photogrammetry, Remote Sensing \& Spatial Information Science, 42(13), 589-596.

Taddia, Y., F. Stecchi., \& A. Pellegrinelli. (2019). Using DJI Phantom 4 RTK drone for topographic mapping of coastal areas. International Archives of the Photogrammetry, Remote Sensing \& Spatial Information Sciences, 42(13), 625-630.

Tahar, K. N. (2015). Efficiency and cost comparison of UAV/Field survey. 2015 International Conference on Space Science and Communication (IconSpace). Malaysia: IEEE, Langkawi.

Trembanis, A. C., Duo, E., Dohner, S., Grottoli, E., \& Ciavola, P. (2017). Quick response assessment of the impact of an extreme storm combining aerial drone and RTK GPS. Nat. Hazards Earth Syst. Sci. 1-7.

Turner, I. L., Harley, M. D., \& Drummond, C. D. (2016). UAVs for coastal surveying. Coastal Engineering, 114, 19-24.

Udin, W. S., \& Ahmad, A. (2014). Assessment of photogrammetric mapping accuracy based on variation flying altitude using unmanned aerial vehicle. IOP Conf. Series: Earth and Environmental Science, 18, 1-7.

Yoo, C. I., \& Oh, T. S. (2016). Beach volume change using UAV photogrammetry Songjung beach, Korea. The International Archives of Photogrammetry, Remote Sensing and Spatial Information Sciences, 41, 1201. 
